\section{PRINCIPAIS GENÓTIPOS DE PAPILOMAVÍRUS HUMANO EM MULHERES RIBEIRINHAS NA AMAZÔNIA BRASILEIRA}

\author{
Main human papillomavirus genotypes in riparian women \\ from the brazilian Amazon
Principales genotipos del virus de papiloma humano de mujeres ribereñas de la Amazonia brasileña

\section{RESUMO}

Objetivo: Avaliar a distribuição dos principais genótipos do papilomavírus humano (HPV) oncogênicos em mulheres de áreas ribeirinhas e pesqueiras de diferentes regiões geográficas da Amazônia brasileira. Métodos: Estudo transversal, realizado no período de 2013 a 2014. Participaram 516 ribeirinhas e pesqueiras maiores de 13 anos, inscritas no Programa de Prevenção do Câncer de Colo Uterino (PCCU) e submetidas à coleta de material cervicovaginal para o Teste Papanicolau, realizado in loco por médico membro da equipe de pesquisadores, pesquisa de DNA/HPV e genotipagem pela Reação em Cadeia da Polimerase (PCR), realizados no Laboratório de Imunopatologia da Universidade Federal do Pará por pesquisadores da mesma equipe, além da coleta de informações como a idade e o tipo de atendimento, também coletados pelos pesquisadores. Todos os dados foram analisados através do Programa Biostat 5.0, considerando diferença significativa quando $p<0,05$. Resultados: A média de idade das mulheres nas comunidades A e B foram, respectivamente, 40 e 39 anos, enquanto nas comunidades C, D e E foi de 37 anos. A prevalência da infecção pelo HPV variou de 7,6\% a 29,2\%. Dentre os tipos oncogênicos pesquisados, os mais frequentes foram HPV52 ( $\mathrm{n}=5 ; 5,15 \%)$, HPV35 ( $\mathrm{n}=4 ; 4,12 \%)$ e HPV58 $(\mathrm{n}=3 ; 3,09 \%)$. Os principais tipos oncogênicos encontrados estão concentrados na região de Itaituba (comunidades A, B) e Bragança (comunidade E). Conclusão: Em todas as localidades estudadas foi encontrado um elevado percentual de infecção, cujo tipo de HPV não foi identificado entre os testados, destacando-se as comunidades $\mathrm{C}$ e $\mathrm{D}$, com $100 \%$ dos casos.

Descritores: Papillomaviridae; Genótipo; Prevalência; Epidemiologia.

\section{ABSTRACT}

Objective: To assess the distribution of the main oncogenic human papillomavirus (HPV) genotypes in women from riparian and fishing areas in different geographical regions of the Brazilian Amazon. Methods: Cross-sectional study conducted from 2013 to 2014. Participants were 516 riparian and fishing women over 13 years old enrolled in the Programa de Prevenção do Câncer de Colo Uterino - PCCUP (Cervical Cancer Prevention Program) and submitted to the collection of cervicovaginal material for the Pap test, carried out in loco by a doctor member of the research team, DNA/HPV research and genotyping by Polymerase Chain Reaction $(P C R)$, carried out in the Laboratorio de Imunopatologia of the Universidade Federal do Pará (Immunopathology Laboratory of the Federal University of Pará) by researchers of the same team. Additionally, information on age and the type of service were also collected by the researchers. All data were analyzed using the Biostat Program 5.0, considering a significant difference when $p<0.05$. Results: The mean age of women in the communities $A$ and $B$ were respectively 40 and 39 years, while in communities $C, D$ and $E$ the mean age was 37 years. The prevalence of HPV infection ranged 7.6 to 29.2\%. Among the studied oncogenic types, HPV52 $(n=5 ; 5.15 \%)$, HPV35 $(n=4 ; 4.12 \%)$ and HPV58 $(n=3 ; 3.09 \%)$ were the most frequent. The main oncogenic types found are concentrated in the regions of Itaituba (communities $A, B$ ) and Bragança (community E). Conclusion: All the studied regions presented a high percentage
Artigo Original
1) Universidade Federal do Pará - UFPA Belém (PA) - Brasil
Recebido em: 08/12/2015 Revisado em: 17/02/2016 Aceito em: 27/03/2016 
of infection whose HPV type was not identified among the tested individuals, especially communities $C$ and D, with $100 \%$ of cases.

Descriptors: Papillomaviridae; Genotype; Prevalence; Epidemiology.

\section{RESUMEN}

Objetivo: Evaluar la distribución de los principales genotipos del virus de papiloma humano (VPH) oncogénicos en mujeres de regiones ribereñas y pesqueras de distintas regiones geográficas de la Amazonia brasileña. Métodos: Estudio transversal realizado entre los periodos de 2013 y 2014. Participaron 516 ribereñas y pesqueras mayores de 13 años inscritas en el Programa de Prevención al Cáncer de Cuello Uterino (PCCU) y que realizaron la recogida de material cervicovaginal para el Test de Papanicolaou realizado in loco por un médico miembro del equipo de investigadores, investigación de ADN/VPH y estudio del genotipo a través de la Reacción en Cadena de la Polimerasa (PCR) realizados en el Laboratorio de Imunopatología de la Universidad Federal de Pará por investigadores del mismo equipo, además de la recogida de informaciones como la edad y el tipo de asistencia. Todos los datos fueron analizados a través del Programa Biostat 5.0 con diferencia significativa para $p<0,05$. Resultados: La media de edad de las mujeres de las comunidades A y B fueron, respectivamente, 40 y 39 años, mientras la de las comunidades $C, D$ y $E$ fue de 37 años. La prevalencia de infección por el VPH varió del 7,6\% al 29,2\%. Entre los tipos oncogénicos investigados los más frecuentes fueron el VPH52 $(n=5 ; 5,15 \%)$, el VPH35 ( $n=4 ; 4,12 \%)$ y el VPH58 $(n=3 ; 3,09 \%)$. Los principales tipos oncogénicos encontrados se concentran en la región de Itaituba (comunidades $A, B$ ) y Bragança (comunidad E). Conclusión: Se encontró un elevado porcentual de infección en todas las localidades estudiadas cuyo el tipo de VPH no ha sido identificado entre los que fueron testados, destacándose las comunidades C y D con el $100 \%$ de los casos.

Descriptores: Papillomaviridae; Genotipo; Prevalencia; Epidemiología.

\section{INTRODUÇÃO}

O câncer de colo uterino representa uma séria ameaça à saúde da mulher, principalmente nos países em desenvolvimento, onde as ações de prevenção e controle não têm alcançado o êxito esperado. A redução dos elevados índices de morbimortalidade associados a essa neoplasia exige o conhecimento dos fatores envolvidos na sua patogênese, dentre eles, a infecção pelo papilomavírus humano (HPV) $)^{(1)}$.

Esse vírus é reconhecido como o principal fator envolvido na gênese do câncer do colo uterino, embora as características genotípicas do vírus, a persistência da infecção e fatores imunológicos do hospedeiro podem influenciar na sua transformação maligna. A infecção persistente com HPV de alto risco, especialmente a causada pelo HPV16 associa-se com frequência ao câncer de células escamosas da cervix uterina e do revestimento epitelial de outros órgãos genitais, tais como vagina, ovários, pênis ${ }^{(1)}$.

Uma metanálise sobre a infecção pelo HPV em nível mundial incluindo países em desenvolvimento mostrou que em países onde é alta a incidência de câncer cervical é elevada a prevalência desse vírus, como na África Subsaariana, América Latina e Índia, afetando principalmente mulheres jovens, reduzindo após 30 anos de idade. Na América Latina, observou-se um segundo pico na prevalência do HPV com efeito em mulheres com idade acima de $55 \operatorname{anos}^{(2)}$.

As estratégias para prevenção e o controle da infecção pelo papilomavírus humano e das lesões precursoras do câncer de colo uterino ainda não estão fortalecidos no Brasil, haja vista os elevados índices de prevalência registrados, em particular na região $\mathrm{Norte}^{(3)}$. O exame colpocitológico realizado regularmente, as práticas adequadas de educação em saúde e a vacinação contra o HPV são ações em fase de implementação que devem ser priorizadas nas unidades básicas de saúde com vista à redução da morbimortalidade por câncer de colo uterino ${ }^{(4,5)}$.

É admitido que a proporção de infecção pelo HPV de alto risco, prevenível pela vacina com os genótipos 16 e 18 variam também por região, com maiores índices na Europa (e talvez na América do Norte) e mais baixa na África Subsaariana $^{(6)}$. Na China, os genótipos HPV52 e HPV56 foram os mais prevalentes e os autores recomendaram vacinas profiláticas de $2^{\mathrm{a}}$ geração, incluindo esses dois genótipos, com vista à maior proteção para as mulheres residentes na área ${ }^{(7)}$.

No Brasil, a prevalência geral de infecção do colo do útero pelo papilomavírus varia entre $13,7 \%$ e $54,3 \%$, e para as mulheres com citologia normal, entre 10,4\% e $24,5 \%{ }^{(8)}$. Em estudo realizado em áreas urbanas e rurais restritas da Amazônia, a prevalência da infecção oscilou em torno de $15 \%{ }^{(9)}$, entretanto, os genótipos do vírus não foram investigados. Ainda são limitadas as estimativas para grupos especiais da Amazônia incluindo populações ribeirinhas, as quais não possuem as mesmas condições de acesso aos serviços de saúde em relação à população geral, dificultando a elaboração de programas com ações voltadas à atenção da mulher ribeirinha.

A identificação dos tipos de HPV de alto risco oncogênico é de grande valor para estudos de prevenção com vacinas, para o monitoramento e controle das lesões associadas e para a adequação e efetividade das ações do Programa de Prevenção do Câncer de Colo Uterino (PCCU) desenvolvido nessas regiões. 
Com isso, a proposta deste estudo foi avaliar a distribuição dos principais genótipos de HPV oncogênicos em mulheres de áreas ribeirinhas e pesqueiras de diferentes regiões geográficas da Amazônia brasileira.

\section{MÉTODOS}

Estudo observacional, transversal, realizado no período de 2013 a 2014. Participaram 516 mulheres inscritas no PCCU (Programa de Prevenção do Câncer de Colo Uterino) desenvolvido em comunidades ribeirinhas de quatro municípios situados em diferentes regiões geográficas do Estado do Pará. Duas comunidades (Comunidades A e B) situadas no Município de Itaituba, sudoeste do Estado do Pará, uma no Município de Limoeiro do Ajurú (Comunidade C), uma no Município do Acará (Comunidade D) e uma comunidade pesqueira no município de Bragança (Comunidade E) - as duas últimas situadas no nordeste paraense. O número de participantes em cada comunidade foi representado por cerca de $20 \%$ da população feminina registrada pelo censo da Estratégia de Saúde da Família do Ministério da Saúde. O número de famílias registrado em cada comunidade do estudo foi de 250, 192, 215, 65 e 230, na Comunidade A, Comunidade B, Comunidade C, Comunidade D e Comunidade E, respectivamente.

Foram incluídas as maiores de 13 anos de idade, que já haviam iniciado a vida sexual, com residência permanente na comunidade ribeirinha ou pesqueira e que compareceram à unidade de saúde para a realização do Teste Papanicolau no período da nossa visita às comunidades, sendo excluídas as mulheres cujo material cervicovaginal não pôde ser analisado para identificação viral, por deterioração e/ou conservação inadequada do material.

Informações sobre a idade e o tipo de atendimento foram obtidas, durante a consulta médica, por pesquisadora da equipe, previamente à coleta do material para exame colpocitopatológico. O material cervicovaginal foi colhido por médico ginecologista membro da equipe de pesquisa, utilizando escova endocervical e espátula de Ayre para realização do Teste Papanicolau e para pesquisa de ácido desoxirribonucleico (DNA) do HPV e genotipagem pela reação em cadeia da polimerase (PCR). O Teste Papanicolau foi realizado por citopatologista, pesquisador da mesma equipe, na própria comunidade; e os resultados foram entregues no local.

A pesquisa de DNA/HPV, realizada através da reação em cadeia da polimerase, foi analisada no Laboratório de Imunopatologia do Núcleo de Medicina Tropical (NMT), da Universidade Federal do Pará (UFPA), por profissionais qualificados nessa área, membros da equipe de pesquisa, e seguiu a metodologia descrita por Pinto, Fuzii e Quaresma ${ }^{(7)}$.
As amostras positivas foram submetidas a PCR em tempo real, utilizando sondas (IDT) para os tipos HPV 6, 11, 16, 18, 31, 33,35, 52 e 58. Para tipagem, foi utilizado Platinum ${ }^{\circledR}$ qPCR SuperMix-UDG kit (Invitrogen, Carlsbad, CA). Para cada reação, adicionou-se $100 \mathrm{ng}$ de DNA, $0.5 \mu \mathrm{l}$ de sondas, $0.2 \mu 1$ de ROX Reference Dye, $10 \mu 1$ de Platinum $^{\circledR}$ qPCR SuperMix-UDG, $0.2 \mu \mathrm{lde} \mathrm{MgCl}$, e água ultrapura qsp 20 $\mu 1$. A amplificação foi realizada no StepOnePlus Real Time Thermocycler (Applied Biosystems ${ }^{\circledR}$ Life TechnologiesTM) e consistiu em 40 ciclos de $95^{\circ} \mathrm{C}$ por $15 \mathrm{~s}$ e $60^{\circ} \mathrm{C}$ por $60 \mathrm{~s}$. Os resultados foram analisados no StepOne Plus software (Applied Biosystems ${ }^{\circledR}$ Life TechnologiesTM).

Todos os dados foram analisados através do programa de análise estatística Biostat 5.0 $0^{(10)}$. Para a análise descritiva das variáveis contínuas, utilizamos média, desvio padrão, frequência absoluta (n) e relativa (\%) para as variáveis categóricas. A análise inferencial foi realizada para comparação das médias de idade entre as cinco comunidades, através do teste ANOVA; e para a comparação das prevalências da infecção pelo HPV, usou-se o teste de metaanálise para várias proporções, considerando diferença significativa quando $\mathrm{p}<0,05$.

Este estudo seguiu os preceitos éticos estabelecidos pela Resolução 466/12 do Conselho Nacional de Saúde (CNS) do Ministério da Saúde do Brasil e foi aprovado pelo Comitê de ética em pesquisa (CEP) do NMT, através do parecer 334.524, em julho de 2013.

\section{RESULTADOS}

A média de idade, a frequência de mulheres que estavam realizando pela primeira vez o exame colpocitológico e a prevalência da infecção pelo HPV nas mulheres das diferentes localidades são apresentadas na Tabela I.

Considerando todas as participantes, a idade variou de 13 a 80 anos, e em cada comunidade $75 \%$ das participantes tinham menos de 60 anos de idade. Em 13\% a 20\% das mulheres a colpocitologia foi realizada pela primeira vez.

A prevalência da infecção HPV nas comunidades variou de 7,6\%, observada na comunidade pesqueira de orla marítima, a $29,2 \%$, prevalência observada em uma das comunidades ribeirinhas do município de Itaituba, região do Tapajós. A prevalência encontrada na Comunidade A (município de Itaituba), 29,2\%, foi maior do que a observada nas demais comunidades, porém, a diferença só foi significativa quando comparada à prevalência registrada na Comunidade A com a registrada nas comunidades $\mathrm{C}, 13,5 \%$ $(p<0,05)$, e E, 7,6\% ( $<<0,01)$, situadas respectivamente em Limoeiro do Ajurú (região do Tocantins) e em Bragança (orla marítima). A menor prevalência foi encontrada na Comunidade E (7,6\%) (município de Bragança). 
Tabela I - Prevalência da infecção pelo HPV em mulheres de áreas ribeirinhas e pesqueiras. Pará, 2013 a 2014.

\begin{tabular}{|c|c|c|c|c|c|c|}
\hline \multirow[t]{3}{*}{ Variáveis } & \multicolumn{2}{|c|}{ Itaituba } & \multirow{2}{*}{$\begin{array}{c}\text { Limoeiro de Ajurú } \\
\text { C }\end{array}$} & \multirow{2}{*}{$\begin{array}{c}\text { Acará } \\
\text { D }\end{array}$} & \multirow{2}{*}{$\begin{array}{c}\text { Bragança } \\
\text { E }\end{array}$} & \multirow{3}{*}{ p valor } \\
\hline & A & B & & & & \\
\hline & $n=195$ & $\mathrm{n}=\mathbf{8 1}$ & $\mathrm{n}=111$ & $n=36$ & $\mathrm{n}=92$ & \\
\hline \multicolumn{7}{|l|}{ Idade (em anos) } \\
\hline Média aritmética & 40 & 39 & 37 & 37 & 37 & $F: 1.7966$ \\
\hline Mediana & 37 & 37 & 36 & 37 & 36 & $\mathrm{p}=0,127$ \\
\hline Mínimo-máximo & $17-80$ & $13-82$ & $14-72$ & $16-71$ & $16-62$ & \\
\hline Tipo atendimento & $\mathrm{n}(\%)$ & $\mathrm{n}(\%)$ & $\mathrm{n}(\%)$ & $\mathrm{n}(\%)$ & n $(\%)$ & \\
\hline $1^{o}$ exame & $39(20,0)$ & $11(13,5)$ & $19(17,1)$ & $5(13,9)$ & $12(13,0)$ & \\
\hline Controle & $156(80,0)$ & $70(86,5)$ & $92(82,9)$ & $31(86,1)$ & $80(87,0)$ & \\
\hline $\mathrm{HPV} / \mathrm{DNA}$ & $57(29,2)$ & $13(16,0)$ & $15(13,5)$ & $5(13,9)$ & $7(7,6)$ & $\begin{array}{l}p<0,05(\mathrm{AxC}) \\
\mathrm{p}<0,01(\mathrm{AxE})\end{array}$ \\
\hline
\end{tabular}

DNA: ácido desoxirribonucléico. $\mathrm{p}<0,05$ difere estatisticamente; Teste Anova - um critério; teste de meta-análise para várias proporções; $\mathrm{p}<0,05$ (AxC) Comunidade A versus Comunidade $\mathrm{C} ; \mathrm{p}<0,01$ (AxE) Comunidade A versus Comunidade E;

Obs.: Comunidades A e B pertencem ao município de Itaituba e estão próximas geograficamente.

Tabela II - Distribuição dos tipos de HPV em comunidades ribeirinhas e pesqueiras de diferentes regiões geográficas. Pará, 2013 a 2014.

\begin{tabular}{|c|c|c|c|c|c|}
\hline $\begin{array}{l}\text { Localidades } \\
\text { Tipos de HPV }\end{array}$ & $\begin{array}{c}\text { Itaituba } \\
\text { A e B } \\
\text { n (\%) } \\
\end{array}$ & $\begin{array}{c}\text { Limoeiro de Ajurú } \\
\mathrm{C} \\
\mathrm{n}(\%) \\
\end{array}$ & $\begin{array}{c}\text { Acará } \\
\text { D } \\
\text { n (\%) } \\
\end{array}$ & $\begin{array}{c}\begin{array}{c}\text { Bragança } \\
\text { E }\end{array} \\
\mathbf{n}(\%) \\
\end{array}$ & $\begin{array}{l}\text { Total } \\
\text { n (\%) }\end{array}$ \\
\hline Não identificados & $52(74,3)$ & $15(100)$ & $5(100)$ & $4(57,1)$ & $76(78,4)$ \\
\hline Identificados & $18(25,7)$ & 0 & 0 & $3(42,9)$ & $21(21,6)$ \\
\hline HPV 6 & $1(1,4)$ & 0 & 0 & $1(14,3)$ & $2(2,1)$ \\
\hline HPV 16 & $1(1,4)$ & 0 & 0 & 0 & $1(1,0)$ \\
\hline HPV 18 & $1(1,4)$ & 0 & 0 & 0 & $1(1,0)$ \\
\hline HPV 31 & $1(1,4)$ & 0 & 0 & 0 & $1(1,0)$ \\
\hline HPV 35 & $4(5,7)$ & 0 & 0 & 0 & $4(4,1)$ \\
\hline HPV 52 & $4(5,7)$ & 0 & 0 & $1(14,3)$ & $5(5,1)$ \\
\hline HPV 58 & $2(2,8)$ & 0 & 0 & $1(14,3)$ & $3(3,1)$ \\
\hline HPV 31,18 & $2(2,8)$ & 0 & 0 & 0 & $2(2,1)$ \\
\hline HPV 33,58 & $1(1,4)$ & 0 & 0 & 0 & $1(1,0)$ \\
\hline HPV 16,52 & $1(1,4)$ & 0 & 0 & 0 & $1(1,0)$ \\
\hline Total & 70 & 15 & 5 & 7 & 97 \\
\hline
\end{tabular}

Dentre os tipos de HPV pesquisados, os mais frequentes foram o HPV52 (este observado em cinco casos isoladamente e em um caso associado ao HPV 16), o HPV35 (que ocorreu em quatro casos isoladamente), além do HPV58 (observado em três casos isoladamente e em um caso associado ao HPV33). A PCR/HPV foi positiva em 13,5\% e $13,9 \%$ nas comunidades $\mathrm{C}$ e $\mathrm{D}$, respectivamente; porém, os tipos oncogênicos investigados não foram encontrados. Nas comunidades A e B, em Itaituba, identificamos todos os tipos pesquisados incluindo as infecções duplas, à exceção do HPV11. Na comunidade pesqueira (E), localizada em Bragança, identificamos os tipos HPV6, 52 e 58. Em 78,4\% das mulheres, com infecção confirmada por DNA/HPV, o tipo viral não foi identificado entre os tipos testados (Tabela II). 


\section{DISCUSSÃO}

A prevalência da infecção pelo HPV nas comunidades estudadas variou de $7,0 \%$ a $29,2 \%$, com maiores índices observados nas ribeirinhas do Tapajós, e menores índices na comunidade de pescadores de orla marítima, no município de Bragança.

Admitimos que um conjunto de fatores peculiares à região do Tapajós, incluindo baixas condições socioeconômicas ${ }^{(11)}$, disponibilidade limitada para realização do exame na comunidade, dificuldade de transporte para o acesso ao exame preventivo na área urbana e o aumento da imigração masculina para a região decorrente das atividades garimpeiras de ouro favorecem a transmissão viral na região contribuindo com a elevada prevalência dessa infecção. Por outro lado, a localização mais próxima da área urbana, comunidade pesqueira de Bragança, facilitando o acesso da mulher ao serviço de prevenção, a ausência de atividades extrativistas de ouro nessa região poderiam explicar uma baixa circulação do vírus HPV e, portanto, uma menor prevalência dessa infecção. Os achados foram diferentes daqueles obtidos por um estudo em populações ribeirinhas de Abaetetuba e Tucuruí, que encontrou prevalências mais elevadas nos municípios que fazem parte também da região do rio Tocantins, $11,4 \%$ e $14,2 \%$, respectivamente ${ }^{(9,12)}$.

Os poucos estudos realizados em comunidades rurais e ribeirinhas no Estado do Pará mostraram prevalências com pequenas variações. Em Tucuruí, a prevalência foi de $14,2 \%^{(9)}$ e em Abaetetuba, $11,4 \%{ }^{(12)}$, resultado semelhante às prevalências encontradas nas comunidades ribeirinhas B (16\%), C (13,5\%) e D (13,9\%). Na década passada, um estudo realizado com mulheres ameríndias do Estado do Pará registrou uma frequência de $42,85 \%$ de HPV em amostras cervicais avaliadas por métodos de biologia molecular ${ }^{(13)}$, achados que sugerem a necessidade de maior atenção a esses grupos tradicionais da Amazônia.

No Brasil, a maioria dos estudos sobre infecção pelo papilomavírus humano envolvendo populações urbanas, com melhor acesso aos serviços de saúde e ao conhecimento das medidas preventivas, registrou prevalências variáveis. Na região Sudeste, recentemente, observou-se uma variação de $13,7 \%$ a $54,3 \%{ }^{(8)}$, enquanto na região Norte a prevalência na década passada foi de $12,6 \%{ }^{(14)}$. Em mulheres do sul do Brasil, foi encontrada prevalência de $18,2 \%{ }^{(15)}$, enquanto em mulheres de um município do Nordeste verificouse prevalência de $10,68 \%{ }^{(16)}$. Os achados encontrados na maioria das comunidades ribeirinhas estão dentro das variações encontradas em mulheres de área urbana, entretanto, a situação é mais preocupante, haja vista as dificuldades de acesso ao programa de prevenção e controle para essas mulheres.
Dentre os nove tipos de HPV testados no corrente estudo, foram identificados sete tipos oncogênicos ou de alto risco, HPV $16,18,31,33,35,52$ e 58 , correspondendo a $22 \%$ das amostras positivas para HPV subtipadas. As amostras das mulheres de Limoeiro do Ajurú, Comunidade C, e do Acará, Comunidade $\mathrm{D}$, não apresentaram positividade para os subtipos testados. A comunidade estudada no município de Bragança, Comunidade E, apresentou dois dos subtipos de alto risco oncogênicos testados, HPV52 e 58. Esses mesmos tipos foram encontrados em mulheres com câncer de colo uterino de sete estados dos Estados Unidos, no entanto, quando avaliados na população geral os autores desse estudo encontraram os tipos HPV16 e o HPV18 como os mais prevalentes ${ }^{(17)}$, à semelhança de estudos com mulheres de Portugal ${ }^{(18)}$ e do Canadá( ${ }^{(19)}$

Os subtipos identificados em Bragança, Comunidade $\mathrm{E}$, são mais próximos dos encontrados em mulheres da China onde prevaleceram os HPV52, 16 e $58^{(20)}$. Outro estudo também na China ${ }^{(21)}$ identificou os tipos HPV 16, 33, 52 e 58 como os mais frequentes subtipos identificados. Em mulheres coreanas ${ }^{(22)}$, verificaram-se maiores prevalências de HPV 16, 58 e 52 em mulheres com lesões intraepiteliais escamosas de baixo grau (LIEBG) e o HPV58 como o segundo tipo mais prevalente nas mulheres com citologia normal e com lesões intraepiteliais escamosa de alto grau (LIEAG), enquanto nas mulheres com câncer invasivo foi o terceiro mais prevalente. Esses achados sugerem que os tipos de HPV identificados em Bragança estão próximos daqueles observados em países asiáticos.

As comunidades A e B de Itaituba apresentaram diferenças interessantes em relação às outras comunidades. Todos os subtipos oncogênicos testados foram encontrados, mostrando os subtipos 18,35 e 58 como os mais frequentes e o HPV16 como o menos frequente. Em estudo envolvendo indígenas da região, o HPV16 foi pouco frequente em relação aos tipos HPV18 e $58^{(13)}$ e ausente no estudo com ribeirinhas no município de Abaetetuba, onde foi encontrado apenas um caso com HPV 58 ao lado de outros menos frequentes ${ }^{(12)}$. Os subtipos de HPV encontrados nas comunidades de Itaituba, comunidades A e B, são similares aos das mulheres da África Subsaariana que apresentaram baixa frequência do tipo 16, mas outros tipos oncogênicos foram mais frequentes, tais como os HPV 31 , 33, 35 e HPV $18^{(6)}$. O HPV 58 a semelhança da prevalência encontrada em um estudo na $\mathrm{China}^{(7)}$ foi o mais frequente subtipo encontrado dentre os testados, sendo identificado em todos os estudos envolvendo ribeirinhas nessa região.

Ressalta-se que a seleção amostral por conveniência das populações estudadas foi a principal limitação deste estudo, uma característica da maioria dos estudos envolvendo ribeirinhos, como consequência das dificuldades pertinentes às condições socioambientais. 


\section{CONCLUSÃO}

Os principais tipos oncogênicos encontrados foram HPV35, HPV52 e HPV58 concentrados na região de Itaituba (comunidades A e B) e Bragança (Comunidade E). Em todas as localidades estudadas foi encontrado um elevado percentual de infecção, cujo tipo de HPV não foi identificado entre os testados, destacando-se as comunidades C e D, com 100\% dos casos. Dessa forma, o risco de desenvolver câncer de colo uterino pode estar relacionado a subtipos que não são cobertos pela vacina tetravalente, recentemente disponibilizada no Brasil.

\section{REFERÊNCIAS}

1. Crosbie EJ, Einstein MH, Franceschi S, Kichner C. Human papillomavirus and cervical cancer. Lancet. 2013;382(9895):889-99.

2. Franceschi S, Herrero R, Clifford GM, Snijders PJ, Arslan A, Anh PT et al. Variations in the age-specific curves of human papillomavirus prevalence in women worldwide. Int J Cancer. 2006;119(11):2677-84.

3. Ministério da Saúde (BR), Instituto Nacional do Câncer - INCA, Coordenação Geral de Ações Estratégicas, Coordenação de Prevenção e Vigilância. Estimativa 2016: incidência de câncer no Brasil. Rio de Janeiro: INCA; 2015.

4. Santos UM, Souza SEB. Papanicolaou: diagnóstico precoce ou prevenção do câncer cervical uterino? Rev Baiana Saúde Pública. 2013;37(4):941-51.

5. Krabbe EC, Padilha AS, Henn A, Molin DBD, Teixeira KJ, Abreu PSA Junior et al. Vacina contra o HPV e a prevenção do câncer de colo do útero: uma necessidade de avanço na prática cotidiana da ciência da saúde. RevInt. 2015;3(1):237-44.

6. Clifford GM, Gallus S, Herrero H, Muñoz N, Snijders PJF, Vaccarella $\mathrm{S}$ et al. Worldwide distribution of human papillomavirus types in cytologically normal women in the International Agency for Research on Cancer HPV prevalence surveys: a pooled analysis. Lancet. 2005;366 (9490):991-8.

7. Chen Q, Xie LX, Qing ZR, Li LJ, Luo ZY, Lin $\mathrm{M}$ et al. Epidemiologic Characterization of human papillomavirus infection in Rural Chaozhou, Eastern Guangdong Province of China. PLoS One. 2012;7(2):e32149.

8. Ayres ARG, Silva GA. Prevalência de infecção do colo do útero pelo HPV no Brasil: revisão sistemática. Rev Saúde Pública. 2010;44(5):963-74.
9. Pinto DS, Fuzii HT, Quaresma JAS. Prevalência de infecção genital pelo HPV em população urbana e rural da Amazônia Oriental Brasileira. Cad Saúde Pública 2011;27(4):769-78.

10. Ayres M, Ayres M Jr, Ayres DL, Santos AS. BioEstat 5.0: aplicações estatísticas nas áreas das ciências biológicas e médicas. Belém: Mamirauá; 2007.

11. Lima ACM. Estado nutricional e desenvolvimento motor de crianças ribeirinhas expostas ao mercúrio no estado do Pará- Amazônia brasileira [tese]. Belém: Universidade Federal do Pará; 2014.

12. Duarte DV, Brito EB, Canto ASS, Ishikawa EAY, Pinheiro JG, Costa JHG, et al. Frequência e genotipagem do Papilomavírus Humano em mulheres de comunidades ribeirinhas do Município de Abaetetuba, Pará, Brasil. Rev Pan-Amazônica Saúde. 2010;1(3):75-82.

13. Brito EB, Martins SJ, Menezes RC. Human papillomavíruses in Ameridian women from Brazilian Amazonian. Epidemiol Infect. 2002;128(3):485-9.

14. Noronha V, Cruz EM, Naum-Pinho C, Mello W, Noronha R, Silveira I, et al. Papilomavirus humano em mulheres submetidas à colpocitologia oncótica. DST J Bras Doenças Sex Transm. 2006;18(2):130-6.

15. Oliveira GR, Vieira VC, Barral MFM, Döwich V, Soares MA, Gonçalves CV et al. Fatores de risco e prevalência da infecção pelo HPV em pacientes de Unidades Básicas de Saúde e de um Hospital Universitário do Sul do Brasil. Rev Bras Ginecol Obstet. 2013;35(5):226-32.

16. Almeida JA, Alencar SMF, Fuzii HT, Sanches BES, Pinheiro DN, Pinheiro MCN. Prevalência e fatores de risco de infecção pelo HPV em mulheres atendidas no município de Imperatriz - MA. Pesquisa em Saúde (Belém). 2015;14:57-63.

17. Hopenhayn C, Christian A, Christian WJ, Watson M, Unger ER, Lynch CF et al. Prevalence of human papillomavirus types in invasive cervical cancers from seven US cancer registries prior to vaccine introduction. J Low Genit Tract Dis. 2014;18(2):182-9.

18. Félix A, Alemany L, Tous S, Sanjosé S, Bosch FX. HPV distribution in cervical cancer in Portugal. A retrospective study from 1928 to 2005. Papillomavirus Res. 2016;2:41-5.

19. Tricco AC, Ng CH, Gilca V, Anonychuk A, Pham B, Berliner S. Canadian oncogenic human papillomavirus cervical infection prevalence: systematic review and meta-analysis. BMC Infect Dis. 2011;11:235 
20. Gu Y, Yi M, Xu Y, Zhao H, Fu F, Zhang Y. Genotype distribution characteristics of high-risk human papillomaviruses in women from Shanghai, China. Epidemiol Infect. 2016;144(7):1482-9.

21. Baloch Z, Yuan T, Wang B, Tai W, Feng Y, Liu Y et al. Ethnic and Geographic Variations in HPV Prevalence and Genotype Distribution in North-Western Yunnan, China. J Med Virol. 2016;88(3):532-40.

22. Bae JH, Lee SJ, Kim CJ, Hur SY, Park YG, Lee WC. Human Papillomavirus (HPV) type distribution in korean women: a meta-analysis. J Microbiol Biotechmol. 2008;18(4):788-94.

\section{Endereço para correspondência:}

Maria da Conceição Nascimento Pinheiro Núcleo de medicina tropical da UFPA Av. Generalíssimo Deodoro, 92 Bairro: Umarizal CEP 66055-240 - Belém - PA - Brasil E-mail: mconci@ufpa.br 